\title{
Redox Reactions in Sodium Alginate Beads
}

\author{
Matthias Ducci* \\ Department of Chemistry, University of Education Karlsruhe, Karlsruhe, Germany \\ *Corresponding author: ducci@ph-karlsruhe.de
}

Received January 16, 2019; Revised February 18, 2019; Accepted March 07, 2019

\begin{abstract}
In this article, novel experiments on the topic of redox reactions are presented. These reactions take place in small sodium alginate beads, containing some of the reactants. By immersing the beads in various solutions, the $\mathrm{pH}$-dependence of the redox potentials of some redox systems and different redox states can be visualized by eye.
\end{abstract}

Keywords: redox potential, redox reaction, sodium alginate

Cite This Article: Matthias Ducci, "Redox Reactions in Sodium Alginate Beads." World Journal of Chemical Education, vol. 7, no. 2 (2019): 40-44. doi: 10.12691/wjce-7-2-2.

\section{Introduction}

Redox reactions are of fundamental importance in technology and everyday life since many productions, metabolic and combustion processes are based on exactly this kind of electron transfer reactions. Hence, this topic, as a form of the donor-acceptor principle, is given consideration in the school education plans throughout the world. The redox potential of a redox system depends on the concentrations of the ion species occurring. If homogeneous redox systems are involved in a reaction, this frequently means that the $\mathrm{pH}$ value plays a decisive role whether a chemical reaction takes place or not (i.e. whether oxonium or hydroxide ions occur).

The central concept of the following, newly developed experiments is to perform redox reactions in so-called alginate beads. As a result, the above connections become particularly visible through optical visualisation and are, therefore, easier to understand for students.

\section{Alginate Beads from Sodium Alginate}

This section briefly describes the alginic acid and its salts, i.e. the alginates, as well as the formation of alginate beads.

Stanford, a British chemist and pharmacist, succeeded for the first time in 1880 in deriving alginic acid from brown algae in which it forms the structural element of cell walls. Today, alginic acid and its salts are used in the food industry as emulsifying, gelling, coating and thickening agents. They may also serve as a wound dressing and impression material for medical purposes.

From a chemical point, alginates are salts of polyuronic acids. The monomeric blocks are the anions of the two uronic acids $\alpha$-L-guluronic acid and $\beta$-D-mannuronic acid (Figure 1 ) which, at varying ratios, are 1,4 glycosidically bonded to form long chains (degree of polymerisation: 100-3000).
Both homopolymeric blocks (MM and GG blocks) and sequences with an alternating structure (MG or GM blocks) occur. The presence of certain metal ions, such as copper(II) ions or calcium ions, causes gelling. Here, first of all the GG blocks are essential since, in contrast to the MM blocks, they exhibit a zigzag structure. If two or more molecules cluster in a suitable manner, cavities are formed in which the metal ions become deposited and coordinatively bonded, thus forming three-dimensional structures. Figure 2 depicts a model of this process.

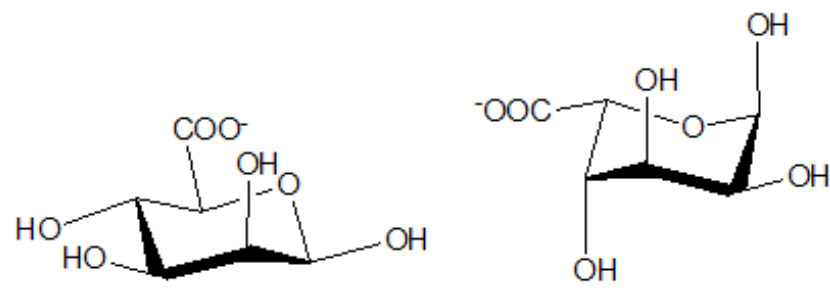

Figure 1. Molecular formulas of $\beta$-D-mannuronate (left) and $\alpha$-L-guluronate (right)

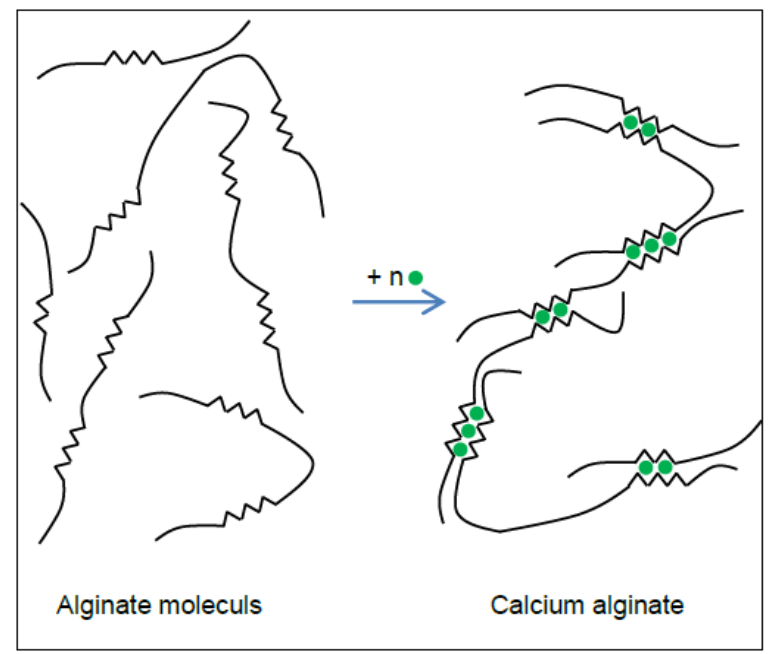

Figure 2. Model of the gelation process (the zigzag lines symbolise the polyguluronate sequences and the green dots indicate the calcium ions; modified according to [1]) 
The gelation process can be utilised to produce socalled alginate beads. To this end, sodium alginate is dissolved in water by heating, and subsequently added dropwise to an aqueous calcium salt solution. When immersing in the solution, the peripheral zone of the drop gelates immediately. As a result, a spherical calcium alginate shell sparingly soluble in aqueous solutions is formed, enclosing the sodium alginate solution. Alginate beads produced in this way are depicted in Figure 3.

Bioprocess engineering is using such alginate beads for immobilizing biocatalysts. Enzymes are being trapped in theses beads by mixing with an aqueous alginate solution first before adding them dropwise to an aqueous calcium chloride solution (encapsulation) [2,3].

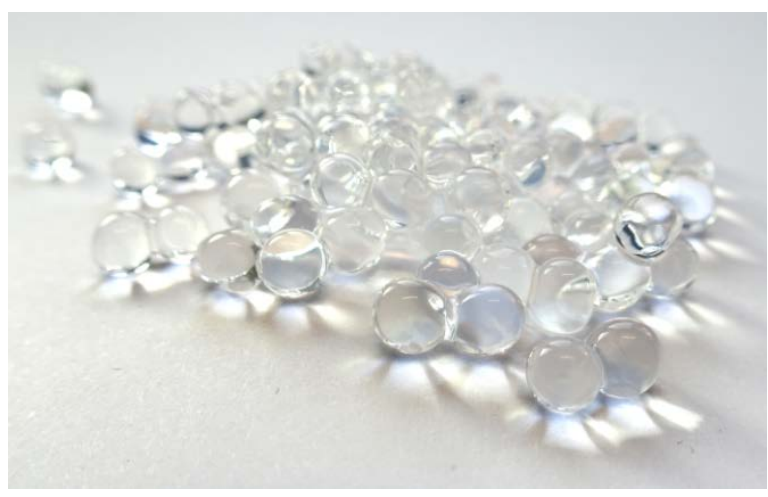

Figure 3. Alginate beads have a shell consisting of calcium alginate sparingly soluble in water (Photograph: Ducci)

A very popular book of experiments in Germany has taken up alginate beads. There, it is suggested to add an indicator to the sodium alginate solution before dripping it into a calcium chloride solution [4]. In this way, indicator beads can be formed. They are transferred then into aqueous solutions with different $\mathrm{pH}$ values. The oxonium or hydroxide ions can diffuse through the calcium alginate shell and the beads change their colour depending on the $\mathrm{pH}$ value and the indicator used (cf. Figure 4).

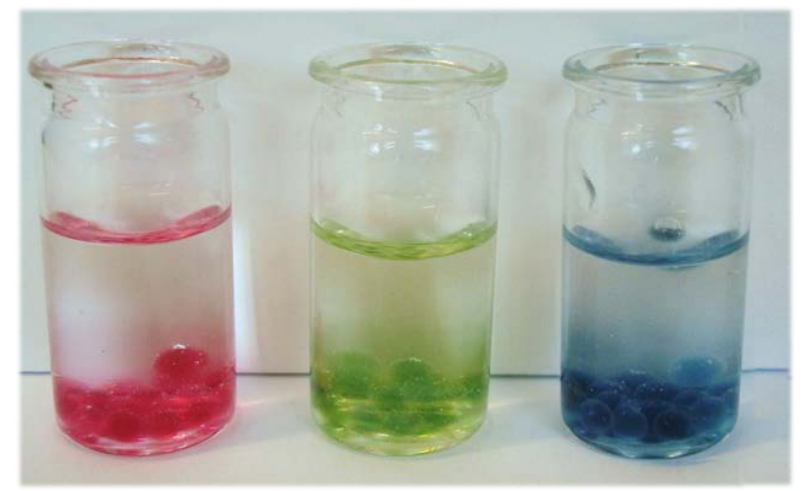

Figure 4. Alginate balls with enclosed universal indicator in acidic, neutral and alkaline solutions (from left to right) (Photograph: Ducci)

In this respect, the author of this paper has developed a fascinating variation. He suggests in [5] to transfer the fluorescent dye pyranine into the beads. Pyranine is a polycyclic, aromatic hydrocarbon with the systematic name trisodium 8-hydroxypyrene-1,3,6-trisulfonate. In neutral and alkaline aqueous solutions, pyranine exhibits an intense yellow-green fluorescence even in daylight and a green fluorescence when exposed to UV light. Therefore, this dye is also used as a tracer in hydrology and as a highlighter dye. Upon acidification, the equilibrium depicted in Figure 5 shifts to the left. The pyranine solution decolourises as a result of a reduction of the $+\mathrm{M}$ effect of the auxochrome group and fluoresces blue under UV light.

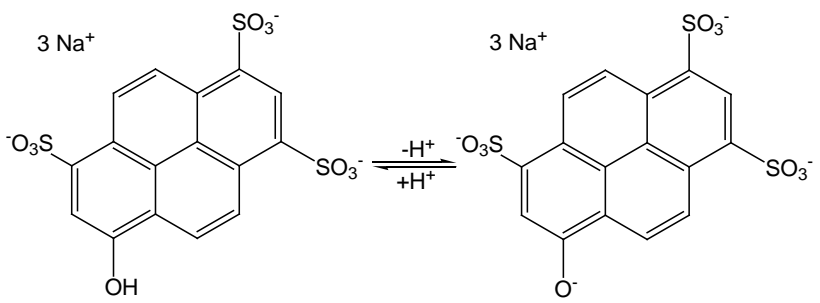

Figure 5. The fluorescent dye pyranine

The pyranine beads fluoresce intensely green under UV light. In an acidic solution $(\mathrm{pH}=1)$ they assume a blue fluorescence (cf. Figure 6).

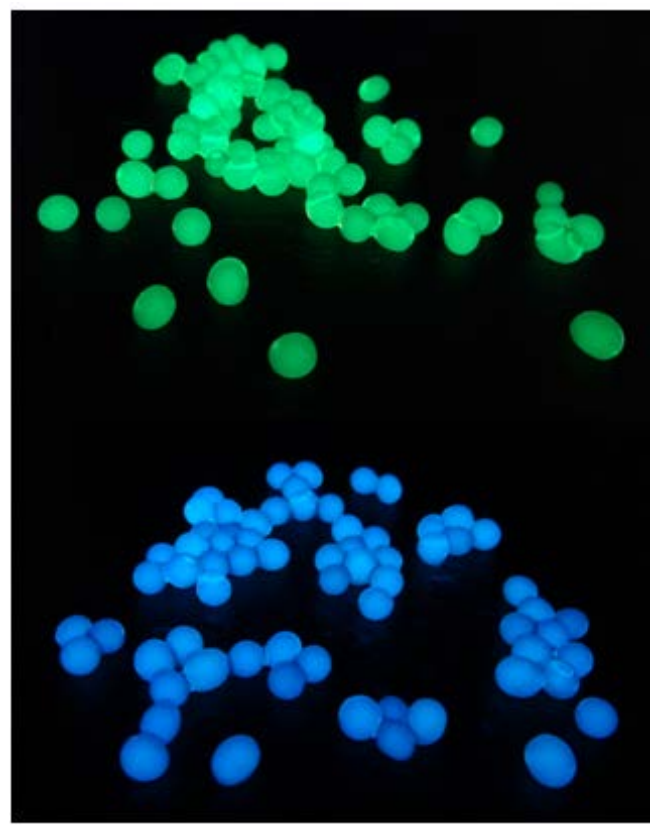

Figure 6. Alginate beads containing the fluorescent dye pyranine when irradiated by a UV lamp (above, $\lambda=365 \mathrm{~nm}$ ). Below: The same alginate beads exposed to UV light following treatment in a strongly acidic solution. (Photographs: Ducci, [5])

\section{Redox Reactions in Alginate Beads}

The redox reaction in alginate beads can be demonstrated by means of the oxidation of iodide ions by nitrate ions:

$$
2 \mathrm{NO}_{3}{ }^{-}+6 \mathrm{I}^{-}+8 \mathrm{H}^{+} \rightarrow 2 \mathrm{NO}+3 \mathrm{I}_{2}+4 \mathrm{H}_{2} \mathrm{O}
$$

Potassium iodide, sodium nitrate and, if appropriate, starch are dissolved in a sodium alginate solution which is subsequently added dropwise to a calcium chloride solution. The resulting alginate beads are colourless; hence, initially no reaction takes place between the enclosed substances. This situation changes as soon as the alginate beads are covered with an acidic solution and oxonium ions diffuse into the inside of the beads. They 
cause an increase of the strongly $\mathrm{pH}$-dependant redox potential of the nitrate ions, namely above the redox potential of the redox pair $\mathrm{I}^{-} / 1 / 2 \mathrm{I}_{2}$. As a result, the redox reaction occurs as formulated above. After some few seconds the alginate beads develop a brown periphery (in the presence of starch it is blue or purple due to the formation of the iodine-starch complex). As the experiment progresses, the colour change extends to the inside of the alginate beads (cf. Figure 7). This experiment can be also performed for quantitative considerations of the students by using the Nernst equation [6].

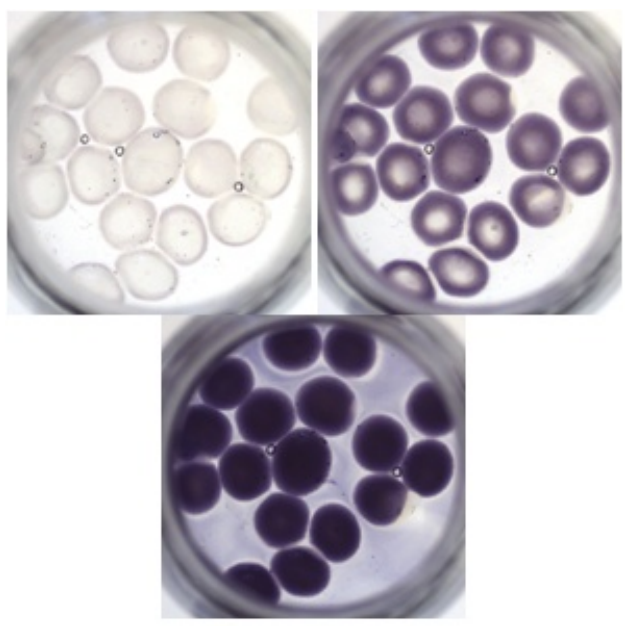

Figure 7. Alginate beads loaded with starch, sodium nitrate and potassium iodide in hydrochloric acid (from left to right: some few seconds after covering with diluted hydrochloric acid; after about $30 \mathrm{~s}$; after about $2 \mathrm{~min}$ ). When the photographs were taken, the glass vessel was standing on a light panel. (Photographs: Ducci)

The alginate beads, now containing the iodine-starch complex, may serve as educts for another redox reaction. To this end, they are transferred from the hydrochloric solution directly into an alkaline sodium thiosulfate solution. The alginate beads decolourise increasingly from the outside to the inside (cf. Figure 8). After about 8 min they are completely colourless.

The thiosulfate ions diffuse into the alginate beads and act there as a reducing agent. A reduction from iodine to iodide ions takes place and the iodine-starch complex is destroyed. During this process the thiosulfate ions are oxidised to form tetrathionate ions:

$$
\begin{gathered}
\mathrm{I}_{2}+2 \mathrm{e}^{-} \rightarrow 2 \mathrm{I}^{-} \\
2 \mathrm{~S}_{2} \mathrm{O}_{3}{ }^{2-} \rightarrow \mathrm{S}_{4} \mathrm{O}_{6}{ }^{2-}+2 \mathrm{e}^{-}
\end{gathered}
$$
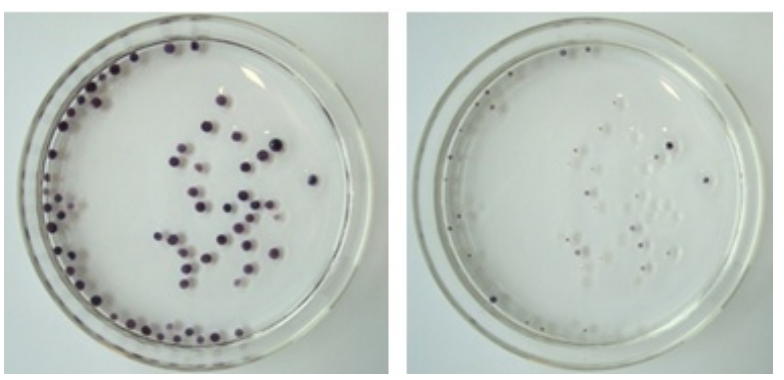

Figure 8. Iodine-starch complex alginate beads in alkaline sodium thiosulfate solution (left: about 2 min following the addition of the beads to the solution; right: after about $7 \mathrm{~min}$ ). (Photographs: Ducci)
Alginate beads can be also used to impressively display the different (fairly stable) oxidation states of manganese. In neutral, aqueous solutions the permanganate ion is reduced to manganese dioxide $\left(\mathrm{MnO}_{2}\right)$ in redox reactions using suitable reactants, whereas in alkaline solutions the green manganate (IV) ion $\left(\mathrm{MnO}_{4}{ }^{2-}\right.$ ion) and in acidic solutions the colourless $\mathrm{Mn}^{2+}$ ion occur. These colours can be observed when alginate beads with enclosed sodium permanganate are immersed in sodium sulfite solutions of a suitable $\mathrm{pH}$ value (cf. Figure 9). The relating reactions are

a) in neutral solution

$$
2 \mathrm{MnO}_{4}{ }^{-}+3 \mathrm{SO}_{3}{ }^{2-}+\mathrm{H}_{2} \mathrm{O} \rightarrow 2 \mathrm{MnO}_{2}+3 \mathrm{SO}_{4}{ }^{2-}+2 \mathrm{OH}^{-}
$$

b) in alkaline solution

$$
2 \mathrm{MnO}_{4}{ }^{-}+\mathrm{SO}_{3}{ }^{2-}+2 \mathrm{OH}^{-} \rightarrow 2 \mathrm{MnO}_{4}{ }^{2-}+\mathrm{SO}_{4}{ }^{2-}+\mathrm{H}_{2} \mathrm{O}(5)
$$

c) in acidic solution

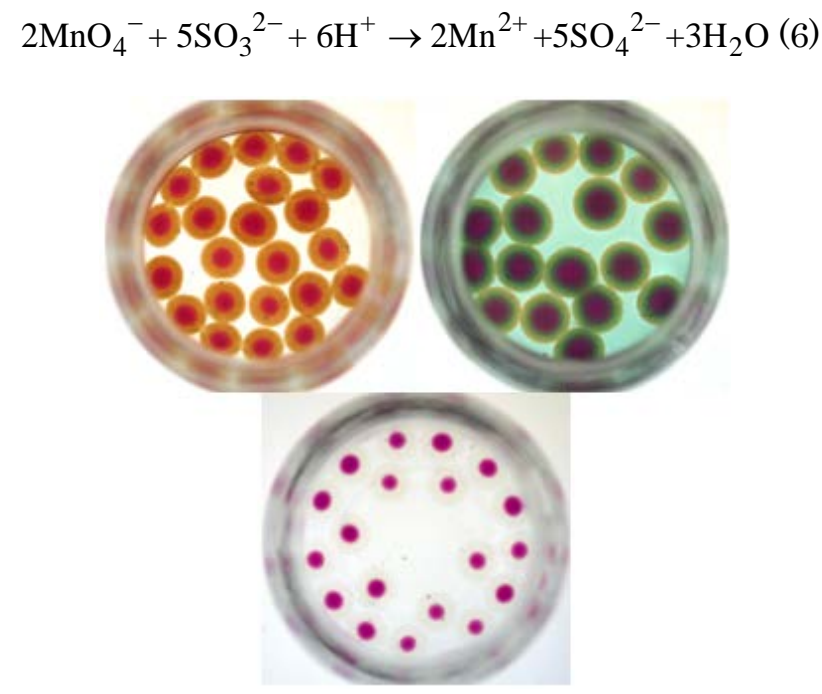

Figure 9. Alginate beads with enclosed sodium permanganate in neutral, alkaline and acidic sodium sulphite solutions (from left to right; the photographs were taken about 2 min after covering) (Photographs: Ducci)

After some few minutes, the green alginate beads assume also a brown colour from the outside to the inside. The reason is the subsequent reactions of the manganate (VI) ion. These reactions can be formulated as follows:

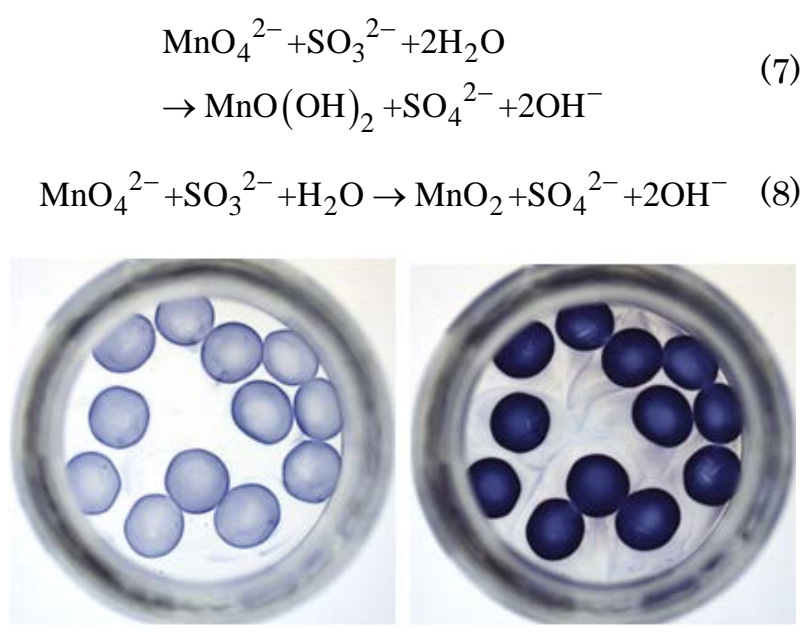

Figure 10. Alginate beads loaded with starch as well as iodide and iodate ions in strongly diluted sulphuric acid solution (left: some few seconds after immersion; right: after 2 to 3 min) (Photographs: Ducci) 
Finally, a comproportionation reaction in alginate beads is described. To this end, alginate beads are required to which potassium iodide, potassium iodate and starch have been transferred. Then, they are covered with a sulphuric solution. After a few moments, the initially colourless beads form a weakly blue "skin". During the following 30 to $60 \mathrm{~s}$, the entire be ad assumes a blue colour. It becomes still more intense during the next 1 to 2 min (cf. Figure 10).

The $\mathrm{H}^{+}$ions diffusing into the alginate beads cause the comproportionation reaction during which elemental iodine is formed:

$$
\mathrm{IO}_{3}{ }^{-}+5 \mathrm{I}_{3}{ }^{-}+6 \mathrm{H}^{+} \rightarrow 3 \mathrm{I}_{2}+3 \mathrm{H}_{2} \mathrm{O} \text {. }
$$

Here again, the diffusion of $\mathrm{H}^{+}$ions into the alginate beads as a result of the $\mathrm{pH}$ dependence of the iodate redox potential is of essential importance for the progress of the formulated redox reaction. In a subsequent reaction, also pentaiodide ions are formed:

$$
2 \mathrm{I}_{2}+\mathrm{I}^{-} \rightarrow \mathrm{I}_{5}^{-}
$$

They accumulate in the hydrophobic cavity of the amylose helix and, as a result of the accumulation of further iodide molecules, form the blue iodine-starch complex.

\section{Experimental}

\subsection{Fluorescent Alginate Beads with Pyranine (cf. Figure 6)}

Solution I: $0.1 \mathrm{~g}$ sodium alginate are weighed and transferred into a test tube. A yellow highlighter serves as the pyranine source. (Note: Not all yellow highlighters contain pyranine. Those highlighters are suited where lines drawn with them on paper can be decolourised by dabbing with $1 \mathrm{~mol}$ sulphuric acid.) By means of scissors, a strip is cut out from a filter paper (about $3 \mathrm{~cm} \times 5 \mathrm{~cm}$ ). An area of $3 \mathrm{~cm} \times 3$ on both sides of the strip is painted using the highlighter. Afterwards, the painted strip is reciprocated in $10 \mathrm{~mL}$ water in a $25 \mathrm{~mL}$ beaker until most of the dye is dissolved. This solution is added to the sodium alginate in the test tube. Alternatively, also some few crystals of pure pyranine may be used instead of the highlighter.

The mixture is heated using a Bunsen burner, while being shaken vigorously (it may boil for a moment; however, pyrolysis should be avoided). Then, the mixture is stirred by means of a glass rod. This step needs to be repeated twice o thrice until the entire sodium alginate is dissolved.

Solution II: 0.5 g calcium chloride are dissolved in 50 $\mathrm{mL}$ water in a $100 \mathrm{~mL}$ beaker.

Using a $1 \mathrm{~mL}$ dropping pipette, 30 drops (drop by drop!) of solution I is added to solution II. This may also be done under UV light. Yellow alginate beads (with an intense green fluorescent colour under UV light) are formed.

The solution with the alginate beads is poured through a fine mesh tea strainer and the alginate beads remaining in the tea strainer are rinsed with water. Then, the alginate beads are transferred into a $25 \mathrm{~mL}$ beaker. About $5 \mathrm{~mL}$ hydrochloric acid, $\mathrm{c}(\mathrm{HCl})=2 \mathrm{~mol} / \mathrm{L}$, are added under UV light. The fluorescence of the beads changes from green to blue.

\subsection{Blue Iodine-Starch Alginate Beads (cf. Figures $7+8$ )}

Solution I: $0.15 \mathrm{~g}$ sodium alginate are added to $5 \mathrm{~mL}$ water in a test tube. The mixture is heated by means of a Bunsen burner, while being shaken vigorously (it may boil for a moment). Then, the mixture is stirred by means of a glass rod. This step needs to be repeated twice o thrice until the entire sodium alginate is dissolved.

Solution II: $0.2 \mathrm{~g}$ starch are weighed and transferred into a test tube with $5 \mathrm{~mL}$ water. The starch is dissolved, while being moderately heated using a Bunsen burner. After the solution has cooled down, $1 \mathrm{~g}$ sodium nitrate and $0.2 \mathrm{~g}$ potassium iodide are added.

Solution III: Solution II is added to solution I (not the other way round!) and stirred using the glass rod.

Solution IV: 0.5 g calcium chloride are dissolved in 50 $\mathrm{mL}$ water in a $100 \mathrm{~mL}$ beaker.

Using a $1 \mathrm{~mL}$ dropping pipette, 20 to 30 drops (drop by drop!) of solution III are added to solution IV. This produces colourless alginate beads.

The solution with the alginate beads is poured through a fine mesh tea strainer and the alginate beads remaining in the tea strainer are rinsed with water. Then, the alginate beads are transferred into a $25 \mathrm{~mL}$ beaker and covered with $5 \mathrm{~mL}$ hydrochloric acid, $\mathrm{c}(\mathrm{HCl})=1 \mathrm{~mol} / \mathrm{L}$. They assume a greyish blue colour from the outside to the inside.

For decolourisation, the dark blue iodine-starch complex beads are transferred into a $25 \mathrm{~mL}$ beaker in which $0.5 \mathrm{~g}$ sodium thiosulfate pentahydrate were dissolved in $5 \mathrm{~mL}$ sodium hydroxide, $\mathrm{c}(\mathrm{NaOH})=2 \mathrm{~mol} / \mathrm{L}$, before.

\subsection{The Redox States of Manganese (cf. Figure 9)}

0.02 g sodium sulfite heptahydrate are dissolved in 5 $\mathrm{mL}$ sodium hydroxide, $\mathrm{c}(\mathrm{NaOH})=2 \mathrm{~mol} / \mathrm{L}$, in a $25 \mathrm{~mL}$ beaker. In a second beaker, $0.1 \mathrm{~g}$ sodium sulfite heptahydrate are dissolved in $5 \mathrm{~mL}$ water. In a third beaker, $0.1 \mathrm{~g}$ sodium sulfite heptahydrate are dissolved in $5 \mathrm{~mL}$ hydrochloric acid, $\mathrm{c}(\mathrm{HCl})=2 \mathrm{~mol} / \mathrm{L}$.

Solution I: $0.1 \mathrm{~g}$ sodium alginate are weighed and transferred into a test tube with $5 \mathrm{~mL}$ water. The mixture is heated by means of a Bunsen burner, while being shaken vigorously (it may boil for a moment). Then, the mixture is stirred by means of a glass rod. This step needs to be repeated twice or thrice until the entire sodium alginate is dissolved.

Solution II: $0.02 \mathrm{~g}$ potassium permanganate are weighed, transferred into a test tube with $5 \mathrm{~mL}$ water and dissolved completely (stir with a glass rod!).

Solution III: Solution II is added to solution I (not the other way round!) and mixed using the glass rod.

Solution IV: $0.5 \mathrm{~g}$ calcium chloride are dissolved in $50 \mathrm{~mL}$ water in a $100 \mathrm{~mL}$ beaker. 
Using a $1 \mathrm{~mL}$ dropping pipette, 30 to 40 drops (drop by drop!) of solution III are added to solution IV. This produces purple alginate beads. The beads are separated from the solution by means of the tea strainer, and rinsed thoroughly with water. Then, the alginate beads are distributed among the three sodium sulfite solutions prepared before in the three small beakers. The colours change as mentioned above.

\subsection{Comportionation in Alginate Beads (cf. Figure 10)}

Solution I: $0.1 \mathrm{~g}$ sodium alginate are weighed and transferred into a test tube with $5 \mathrm{~mL}$ water. The mixture is heated by means of a Bunsen burner, while being shaken vigorously (it may boil for a moment). Then, the mixture is stirred by means of a glass rod. This step needs to be repeated twice or thrice until the entire sodium alginate is dissolved.

Solution II: $0.25 \mathrm{~g}$ starch are weighed and transferred into a large test tube with $25 \mathrm{~mL}$ water. The starch is dissolved, while being moderately heated by means of a Bunsen burner. After the solution has cooled down, $0.02 \mathrm{~g}$ potassium iodate and $0.1 \mathrm{~g}$ potassium iodide are added.

Solution III: $5 \mathrm{~mL}$ of solution II are added to solution I (not the other way round!) and mixed using the glass rod.

Solution IV: 0.5 g calcium chloride are dissolved in 50 $\mathrm{mL}$ water in a $100 \mathrm{~mL}$ beaker.

Using a $1 \mathrm{~mL}$ dropping pipette, about 20 drops (drop by drop!) of solution III are added to solution IV. This produces colourless alginate beads. The solution with the alginate beads is poured through a fine mesh tea strainer and the alginate beads remaining in the tea strainer are rinsed with water. Then, the alginate beads are transferred into a $25 \mathrm{~mL}$ beaker, in which $0,3 \mathrm{~mL}$ sulfuric acid solution, $\mathrm{c}\left(\mathrm{H}_{2} \mathrm{SO}_{4}\right)=0,1 \mathrm{~mol} / \mathrm{L}$, were mixed with $5 \mathrm{~mL}$ water before. The initially colourless beads assume a weakly blue colour becoming more and more intense.

\section{Summary and Outlook}

The paper presents various chemical reactions occurring inside alginate beads. To this end, reactants are transferred into the alginate beads during their formation, whereas other reactants subsequently diffuse through the calcium alginate shell, giving stability to the beads. In this way, the connection, among other things, between the redox behaviour of some redox systems and the $\mathrm{pH}$ value is visualised in an impressive way. In general, these experiments are aesthetically appealing, highly practicable as well as resource-saving and, therefore, sustainable.

Presently, the author develops experiments for organicchemical reactions and ligand exchange reactions in alginate beads (also refer to [7]) as well as for chemoluminescent alginate beads (also refer to [5]).

\section{References}

[1] Ost, A., “Alginate und Carrageenane,“ Philipps-Universität Marburg [Online].

Available: www.chids.de/dachs/expvortr/759Alginate_Ost.doc [Accessed Feb. 25, 2019].

[2] Kayser, O., Averesch, N., Technische Biochemie, Springer, Wiesbaden, 2015, 65-66.

[3] Smidsrød, O., Skjåk-Bræk, G., “Alginate as Immobilisation Matrix for Cells,” TIBTECH, 8 (1). 71-78. 1990.

[4] Brandl, H., Chemische Trickkiste, Aulis, Köln, 2010, 164-166.

[5] Ducci, M., Syskowski, S., "Chemische Reaktionen in Bubble TeaBällchen,” ChiuZ, 52 (6). 390-397. 2018.

[6] Ducci, M., “Jetzt geht's rund - Redoxreaktionen in Alginatbällchen,” CHEMKON, 23 (1). 14-18. 2016.

[7] Ducci, M., “AC meets OC...in Alginatbällchen,” CHEMKON, 24 (2). 88-90. 2017. 